\title{
Electron Localizations in Alloy Exhibiting Nanotwinning ${ }^{\dagger}$
}

\author{
Martin Zelený ${ }^{1,2, *}$, Jan Zemen ${ }^{3}$, Martin Veis ${ }^{2}$, Daniel Král ${ }^{2}$, Ladislav Straka ${ }^{2,4}$ and \\ Oleg Heczko ${ }^{4}$ \\ 1 Faculty of Mechanical Engineering, Brno University of Technology, Technická 2896/2, \\ CZ-616 69 Brno, Czech Republic \\ 2 Faculty of Mathematics and Physics, Charles University, Ke Karlovu 5, CZ-121 16 Prague, Czech Republic \\ 3 Faculty of Electrical Engineering, Czech Technical University in Prague, Technická 2, \\ CZ-166 27 Prague, Czech Republic \\ 4 Institute of Physics of the Czech Academy of Sciences, Na Slovance 2, CZ-182 21 Prague, Czech Republic \\ * Correspondence: zeleny@fme.vutbr.cz \\ + Presented at the 37th International Symposium on Dynamical Properties of Solids (DyProSo 2019), Ferrara, \\ Italy, 8-12 September 2019.
}

Published: 5 September 2019

$\mathrm{Ni}_{2} \mathrm{MnGa}$ is a ferromagnetic shape memory alloy in which a large spontaneous deformation up to $12 \%$ has been observed after application of an external magnetic field [1]. The key to such material functionality is the ferroelastic microstructure of martensite with deep hierarchical twinning up to nanoscale [2]. However, the microscopic origin of the martensitic transformation between the high temperature austenitic and low temperature martensitic phases is not fully understood to date as well as exact origin of nanotwining in martensitic phases. In present work we have used firstprinciples calculations based on density functional theory (DFT) to simulate magneto-optical (MO) Kerr spectra for different phases of $\mathrm{Ni}_{2} \mathrm{MnGa}$ alloy: austenite, nonmodulated martensite without nanotwinning and nanotwined martensite represented by $4 \mathrm{O}$ structure [3]. The MO spectra provide a valuable insight into the mutual dependence of the the structure of the material and electronic structure and magnetic ordering.

The work of Himmetoglu et al. [4] suggests that the Hubbard treatment of the on-site Coulomb interaction of d-electrons localized on $\mathrm{Mn}$ sites $(\mathrm{DFT}+\mathrm{U})$ is required to describe correctly the electronic structure of $\mathrm{Ni}_{2} \mathrm{MnGa}$ alloy. A comparison of the calculated and measured spectra allowed us to estimate the proper value of Coulomb interaction parameter $\mathrm{U}$, which we found significantly smaller than the value proposed in previous works [4,5]. Using smaller $\mathrm{U}$, we obtain a better quantitative agreement with experiment at least in case of elastic constants and lattice parameters in $\mathrm{Ni}_{2} \mathrm{MnGa}$. Comparison of the newly calculated densities of states covering the electron localization then provides a better insight into the origins of martensitic transformation and nanotwinning.

Funding: This work was supported by the Ministry of Education, Youth and Sports of the Czech Republic within the program OP VVV “Excellent Research Teams" under Project CZ.02.1.01/0.0/0.0/15_003/0000487-MATFUN, by the Large Infrastructures for Research, ExperimentalDevelopment and Innovations project "IT4Innovations National Supercomputing Center-LM2015070" and by the Czech Science Foundation under project no. 19$22016 S$.

\section{References}

1. Acet, M.; Mañosa, L.; Planes, A. Magnetic-Field-Induced Effects in Martensitic Heusler-Based Magnetic Shape Memory Alloys. In Handbook of Magnetic Materials; Buschow, K.H.J., Ed.; Elsevier: Amsterdam, The Netherlands, 2011; Chapter 4, Volume 19, pp. 231-289. 
2. Kaufmann, S.; Niemann, R.; Thersleff, T.; Rößler, U.K.; Heczko, O.; Buschbeck, J.; Holzapfel, B.; Schultz, L.; Fähler S. Modulated martensite: why it forms and why it deforms easily. New J. Phys. 2011, 13, 053029.

3. Zelený, M.; Straka, L.; Sozinov, A.; Heczko, O. Ab initio prediction of stable nanotwin double layers and $4 \mathrm{O}$ structure in Ni2MnGa. Phys. Rev. B 2016, 94, 224108.

4. Himmetoglu, B.; Katukuri, V.M.; Cococcioni, M. Origin of magnetic interactions and their influence on the structural properties of $\mathrm{Ni}_{2} \mathrm{MnGa}$ and related compounds. J. Phys. Condens. Matter. 2012, 24, 185501.

5. Koubský, T.; Sedlák, P.; Seiner, H.; Fojtíková, J.; Obata, M.; Oda, T.; Kalvoda, L. Ab Initio Study of Martensitic Transition in Ni2MnGa. Acta Phys. Pol. A 2018, 134, 804.

(C) 2019 by the authors. Submitted for possible open access publication under the terms and conditions of the Creative Commons Attribution (CC BY) license (http://creativecommons.org/licenses/by/4.0/). 